\title{
The Oral Serine Protease Inhibitor WX-671 - First Experience in Patients with Advanced Head and Neck Carcinoma
}

\author{
Jens E. Meyer ${ }^{a} \quad$ Carsten Brocks $^{a} \quad$ Hendrik Graefe $^{a} \quad$ Carola Mala $^{b} \quad$ Natalie Thäns ${ }^{b}$ \\ Markus Bürgle $^{b} \quad$ Annette Rempel $^{c} \quad$ Nicole Rotter $^{\mathrm{a}} \quad$ Barbara Wollenberg $^{\mathrm{a}}$ Stephan Lang ${ }^{\mathrm{d}}$ \\ ${ }^{a}$ Department of Otorhinolaryngology and Facial Plastic Surgery, University Hospital Schleswig Holstein - Campus Lübeck, \\ ${ }^{b}$ Wilex AG, Munich, \\ cFGK Clinical Research GmbH, Munich, \\ ${ }^{\mathrm{d} D e p a r t m e n t}$ of Otorhinolaryngology, Head and Neck Surgery, University Hospital Essen, University Duisburg-Essen, Germany
}

\section{Introduction}

Tumour invasion and metastasis depend on the capacity of tumour cells to coordinate various biological processes such as detachment of cells from their original localisation, cancer cell migration, invasion of cancer cells into surrounding tissue, access to blood and lymphatic vessels and adhesion to and invasion through the endothelium, allowing colonisation at distant sites of the organism. This complex scenario requires the concerted and regulated expression of extracellular proteolytic systems, integrins and adhesion proteins. Degradation of proteins in basement membranes and extracellular matrix is the prerequisite for the invasion of cells and the formation of metastases. This is mediated by various extracellular proteolytic enzymes including serine proteinases, metalloproteinases and cysteine proteinases [1]. There is abundant experimental evidence that the plasminogen activator system plays an essential role in these processes [1-8]. It consists of two serine proteinases, urokinase-type plasminogen activator (uPA) and tissue-type plasminogen activator (tPA), the cell surface $\mathrm{UPA}$ receptor ( $\mathrm{UPAR}$ ) and the plasminogen activator inhibitors 1 and 2 (PAI-1, PAI-2). uPA is agreed to be the enzyme with the major influence on cancer-related processes, whereas the primary role of tPA is the generation of plasmin for fibrinolysis of blood vessels [9]. Besides its proteolytic activity, uPA in concert with uPAR also mediates mitogenic, adhesive and migratory processes [10]. Clinical studies have demonstrated the relevance of UPA, UPAR and PAI-1 in malignant tumours such as breast, ovary, cervical, upper urinary, gastrointestinal, lung, prostate and other cancers. Elevated levels of these factors correlate with increased malignancy and poor patient outcome $[1,7,11,12]$. For head and neck squamous cell carcinoma (HNSCC) the role of the uPA system has been extensively investigated [13-17]. In tumour lysates, it has been demonstrated that both uPA and PAI-1 may play a specific role in the process of invasion and metastasis and might also be of prognostic value in this carcinoma $[18,19]$.

Recently, Wilex developed a serine protease inhibitor of the uPA system, the intravenous drug WX-UK1, and its new orally administered pro-drug WX-671 to treat cancer. Once WX-671 is absorbed, the hydroxyamidino function is reductively converted to the amidino function, thereby generating pharmacologically active WX-UK1. In rat, dog and monkey, WX-671 is effectively absorbed, although with vary- ing rates between species, and readily metabolised to WX-UK1. In rat models, WX-671 has been shown to be efficacious at inhibiting tumour growth and spread. For clinical testing in man, hard gelatine capsules are available that contain WX-671 hydrogen sulphate equivalent to $50 \mathrm{mg}$ and $200 \mathrm{mg} \mathrm{WX-671} \mathrm{(free} \mathrm{base).} \mathrm{The} \mathrm{aim} \mathrm{of} \mathrm{this} \mathrm{study}$ was to evaluate the pharmacokinetics of both the oral pro-drug WX671 and the metabolite WX-UK1 in human tissue and plasma of patients with HNSCC. In addition, the safety and tolerability as well as the effects on the UPA system of WX-671 were assessed.

\section{Patients and Methods}

\section{Study Design, Test Products and Patients}

This investigation was conducted as an open-label, single-arm, phase I study. The study consisted of a 10-day screening period, a 15-day treatment period including visits at day 1 , day 8 and day 15 , a biopsy before the treatment period and at 24 to $72 \mathrm{~h}$ after the last dose, and a follow-up visit 1 week after the last oral dose of WX-671 (table 1). This study was performed in compliance with good clinical practices (GCP) including the archiving of essential documents.

$100 \mathrm{mg}, 200 \mathrm{mg}$ or $400 \mathrm{mg}$ WX-671 was once daily orally administered for 15 days. Eligible patients were sequentially enrolled into these three dose groups. Only after the safety of the smaller applicable dose was established, patients were enrolled in the next higher dose group. In total, 19 patients were included: 6 patients in the 100-mg group, 7 patients in the 200-mg group, 6 patients in the 400-mg group.

Criteria for inclusion were histologically confirmed squamous cell carcinoma of the head and neck in newly diagnosed patients with indication to primary resection or patients with indication to secondary resection after relapse ( $\geq$ T1 primary tumour stage or any T stage with an $\mathrm{N}+$ neck). Additionally all patients had to have a Karnofsky performance scale $\geq 80$, a life expectancy of $>12$ weeks, an age $\geq 18$, normal 12-lead electrocardiograms (ECGs) or only clinically insignificant abnormalities in the judgment of the investigator, and a negative pregnancy test for women of child-bearing potential. The laboratory parameters obtained within the screening period had to be a white blood cell count $\geq 3 \times 10^{9} / 1$, neutrophils

\section{KARGER}

Fax +497614520714

Information@Karger.de

www.karger.com (c) 2008 S. Karger GmbH, Freiburg

Accessible online at:

www.karger.com/brc
Prof. Dr. med. Stephan H. Lang

Hals-Nasen-Ohrenklinik und Poliklinik

Universitätsklinikum Essen

Hufelandstr. 55, 45122 Essen, Germany

Tel. +49 201 723-2481, Fax -5903

stephan.lang@uk-essen.de 
Table 1. Schedule of assessment

\begin{tabular}{|c|c|c|c|c|c|c|c|c|}
\hline \multirow{2}{*}{$\frac{\text { Assessment }}{\text { Study day }}$} & \multicolumn{2}{|c|}{ Screening, baseline } & \multicolumn{4}{|c|}{ Treatment period } & \multicolumn{2}{|l|}{ FU } \\
\hline & -10 to -1 & -4 & $\begin{array}{l}1 \\
\text { pre-dose }\end{array}$ & post-dose & 8 & 15 & $\begin{array}{l}24-72 \mathrm{~h} \\
\text { post-dose }\end{array}$ & $\begin{array}{l}1 \text { week } \\
\text { post-dose }\end{array}$ \\
\hline Informed consent & $\mathrm{x}$ & & & & & & & \\
\hline Inclusion + exclusion criteria & $\mathrm{x}$ & & & & & & & \\
\hline Medical history & $\mathrm{x}$ & & & & & & & \\
\hline Virus serology (Hep, HIV) & $\mathrm{x}$ & & & & & & & \\
\hline Body height & $\mathrm{x}$ & & & & & & & \\
\hline Physical examination & $\mathrm{x}$ & & & & & & & $\mathrm{x}$ \\
\hline Body weight & $\mathrm{x}$ & & & & & & & $\mathrm{x}$ \\
\hline Karnofsky performance & $\mathrm{x}$ & & & & & & & $\mathrm{x}$ \\
\hline ECG & $\mathrm{x}$ & & $\mathrm{x}$ & $\bullet$ & - & - & & $\mathrm{x}$ \\
\hline Vital signs & $\mathrm{x}$ & & $\mathrm{x}$ & - & - & - & & $\mathrm{x}$ \\
\hline Safety laboratory & $\mathrm{x}$ & & $\mathrm{x}$ & - & - & - & & $\mathrm{x}$ \\
\hline Coagulation (PT, PTT) & $\mathrm{x}$ & & $\mathrm{x}$ & - & - & - & & $\mathrm{x}$ \\
\hline Biological marker D-dimer & $\mathrm{x}$ & (x) & $\mathrm{x}$ & & $\mathrm{x}$ & $\mathrm{x}$ & & $\mathrm{xx}$ \\
\hline Biopsy & $\mathrm{x}$ & & & & & & & \\
\hline Resection & & & & & & & $\mathrm{x}$ & \\
\hline Pharmacokinetics & & & & $\mathrm{x}$ & $\mathrm{x}$ & $\mathrm{x}$ & & \\
\hline
\end{tabular}

-: To be taken or measured, respectively, at the assumed maximal concentration of the study drug in plasma $4 \mathrm{~h}$ post intake of dose.

$\mathrm{x}$ : To be taken, measured or performed.

(x): An effort was to be made to collect an additional sample during screening.

$\mathrm{xx}$ : $1-2$ days after surgery and at follow-up.

ECG = Electrocardiogram, FU = follow-up visit, $\mathrm{Hep}=$ hepatitis, $\mathrm{HIV}=$ human immunodeficiency virus, $\mathrm{PT}=$ prothrombin time, PTT = partial thromboplastin time.

$\geq 1.5 \times 10^{9} / 1$, platelets $\geq 100 \times 10^{9} / 1$, haemoglobin $\left.\geq 9 \mathrm{~g} / \mathrm{dl}\right)$, total bilirubin $\leq 1.5 \times$ upper limit of normal (ULN), asparagine aminotransferase, alanine aminotransferase, alkaline phosphatase and gamma glutamyl transferase $\leq 2.5 \times \mathrm{ULN}$, serum creatinine $\leq 2 \times \mathrm{ULN}$ equivalent to a calculated creatinine clearance $>60 \mathrm{ml} / \mathrm{min}$.

All patients had to be able to participate, communicate well with the investigator, comply with the study restrictions and willing to give informed consent to participate and provide a tumour specimen in the course of routinely indicated procedures such as biopsy (pre-dose) and subsequent tumour resection (post-dose).

\section{Safety and Pharmacokinetics in Plasma Samples}

On the visits at day 1, day 8 and day 15, patients received 12-lead ECGs, adverse event (AE) monitoring, routine safety laboratory chemistry, coagulation parameters and a physical examination (including body weight, vitals signs, Karnofsky performance scale).

An AE was defined as any new undesirable medical experience or change of an existing condition that occurred during or after administration of the investigational agent, whether or not it was considered agent related. Abnormal laboratory findings considered by the principal investigator to be clinically significant, e.g. those that were unusual or unusually severe for the population being studied, were also considered AEs. Elective interventions during the study (repeat biopsy, secondary resection) were not required to be reported as AEs.

All AEs occurring during the study were recorded on the patient's AE form and included the following information: a description, date of onset and resolution, severity, intensity, relationship to the investigational agent, action taken, and outcome. AEs were graded according to the National Cancer Institute common toxicity criteria for AEs (CTCAE) version 3.0 (published Dec 12, 2003).

Patients experiencing AEs were followed carefully until the condition re- solved or could not resolve any further, and every effort was made to clarify the underlying cause. Follow-up information related to serious AEs including deaths was forwarded to Wilex by telephone, fax, or by e-mail as soon as relevant data were available.

All abnormal findings were followed until they had returned to normal or could not resolve any further. To assure that any serious AE that occurred up to 30 days after the last study drug dose was reported, the study staff was to contact the patient by phone 1 month after the last dose.

Blood samples (approximately $3 \mathrm{ml}$ ) for analysis of pharmacokinetics were collected $30 \mathrm{~min}$ prior to dosing, 30, 45, 60, $90 \mathrm{~min}, 2,3,4$, and $8 \mathrm{~h}$ after dosing into ethylene diaminetetraacetic acid tubes for the measurement of plasma levels of WX-671 and WX-UK1. The date and the exact time of each sample were recorded in the case report from. Blood samples were centrifuged immediately at room temperature after collection and each plasma sample was transferred to a uniquely labelled safelock Eppendorf tube and stored below $-20^{\circ} \mathrm{C}$ until assayed.

Plasma concentration-time data were analysed by standard model-independent methods using currently approved, validated software. The following parameters were derived for WX-671 and WX-UK1: area under the plasma concentration time curve (AUC), maximum concentration $\left(\mathrm{C}_{\max }\right)$, time to reach maximum plasma concentration $\left(\mathrm{t}_{\max }\right)$, apparent terminal half-life $(\mathrm{t} / 2)$.

\section{Tissue Samples}

Tissue sampling was performed within 24-72 $\mathrm{h}$ after the last study drug intake, performed during routine biopsy and resection. If possible, 1-2 samples each from the tumour centre and adjacent non-tumour tissue as endogenous control were collected.

One aliquot of the sample was to be immediately transferred to a uniquely labelled cryo-tube pre-filled with a defined volume of buffer. Aliquots were to be snap-frozen and stored at $-20^{\circ} \mathrm{C}$. 


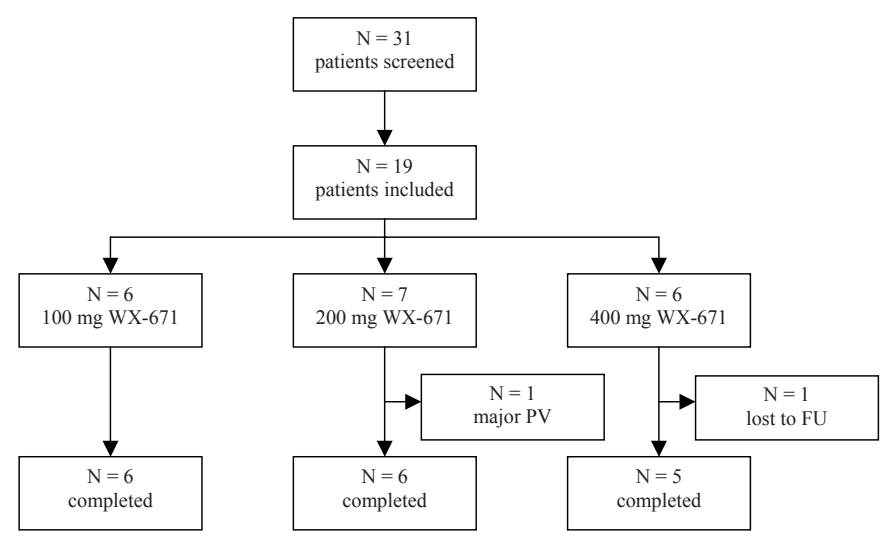

Fig. 1. Patient disposition. $\mathrm{FU}=$ Follow-up, $\mathrm{N}=$ number of patients, $\mathrm{PV}=$ protocol violation.

WX-671 and WX-UK1 target tumour concentrations were determined by extracting native post-treatment samples and subsequent measurement by liquid chromatography-mass spectrometry/mass spectrometry (LCMS/MS) methodology.

\section{Results}

\section{Demographics and Baseline Characteristics}

A total of 19 patients were included in this open-label, single-arm study. 6 patients each received either 100 or $400 \mathrm{mg} \mathrm{WX-671} \mathrm{and} 7$ pa-

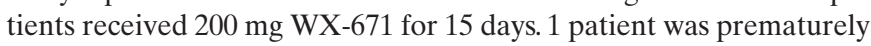
withdrawn due to a major protocol violation; 1 patient was lost to follow-up. Thus, 17 patients completed the study as scheduled (fig. 1). All patients included were Caucasians and most of the patients were male $(13 / 19,68.4 \%)$. The median age of the patients was 55 years, ranging from 42 to 69 years. The mean Karnofsky performance scale index was 93 , consistent with the protocol requirement of being $\geq 80$, and the mean body mass index was $26 \mathrm{~kg} / \mathrm{m}^{2}$, indicating normal weight. There were no meaningful differences between treatment groups, though slight differences were seen probably due to the small number of patients included per treatment arm. As required by the protocol, none of the patients had a significant cardiac disease (New York Heart Association (NYHA) class III or IV) or presented with a human immundeficiency virus or hepatitis infection. The most frequently reported previous and concomitant disease was hypertension (4/19 patients) followed by hypothyroidism (3/19 patients).

All patients presented with newly diagnosed HNSCC and the majority had either a tumour of the larynx (7/19 patients, $36.8 \%$ ) or oropharynx (3/19 patients, $15.8 \%$ ). The primary tumour size was assessed as T2 for almost half of the patients (9/19 patients, $47.4 \%)$ followed by T3, which was reported for $4 / 19$ patients $(21.1 \%)$. Tumour grading showed a grade of 2 for most of the patients (14/19 patients, 73.7\%). Involvement of lymph nodes was reported for $13 / 19$ patients $(68.4 \%)$; however, no distant metastasis was seen in $16 / 19$ patients $(84.2 \%)$; for the remaining 3 patients no assessment was possible $(\mathrm{Mx})$.

Except for those diseases associated with HNSCC, the most commonly reported pathological findings at baseline physical examinations were related to the lymph nodes (11/19 patients, $57.9 \%$ ) consistent with the TNM (tumour, node, metastasis) staging at screening. Abnormal findings in other organ systems were only rarely reported. According to patient diaries, all patients took the medication as scheduled, except for one patient who took an overdose at day 1 (without any serious complications) and was therefore prematurely discontinued.

\section{Pharmacokinetics}

WX-671 was measured in the plasma of HNSCC patients and increased with the dose. $\mathrm{C}_{\max }$ and $\mathrm{AUC}_{\text {last }}$ values of WX-UK1 increased in the low-dose and high-dose group from day 1 to 8 and remained nearly constant from day 8 to 15 . An increase was observed in the intermediate-dose group from day 1 to 8 and from day 8 to 15 . $\mathrm{C}_{\max }$ occurred at $\left(t_{\max }\right)$ 170-360 min post dosing of a 100-mg capsule, at

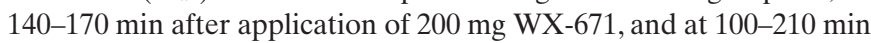
in the high-dose group.

Trough concentrations were similar on days 8 and 15 and essentially reached steady state on day 8 . Trough levels were disproportionally high in the 200-mg group compared to the 100-mg group. Terminal half-life $\left(\mathrm{t}_{1 / 2}\right)$ for WX-671 and WX-UK1 was not calculated because the last plasma sample at $8 \mathrm{~h}$ after dosing was not sufficient to determine a terminal half-life. Therefore, a calculation of clearance (CL) and volume of distribution (VD) was not possible.

\section{Tissue Levels}

A total number of 30 human tissue samples and 14 plasma samples taken after resection of tumour and control tissue were analysed for their content of WX-671 and its active metabolite WX-UK1.

WX-671 was found in tissue in low concentrations that ranged from 10 to $120 \mathrm{ng} / \mathrm{g}$. Approximately the same concentrations were measured in the corresponding plasma samples. No dose dependency could be identified (fig. 2).

WX-UK1 was found in tissue in approximately 10-15-fold higher concentrations than WX-671. The concentrations of WX-UK1 ranged from 9 to $297 \mathrm{ng} / \mathrm{g}$ in the low-dose group, from 129 to $2480 \mathrm{ng} / \mathrm{g}$ in the intermediate- and from 242 to $797 \mathrm{ng} / \mathrm{g}$ in the highest-dose group (fig. 2). Aside from the two highest tissue concentrations in the mediumdose group ( 2480 and $1561 \mathrm{ng} / \mathrm{g}$ ), the tissue levels in the highest-dose group and the medium-dose group were nearly the same. A dose-dependent increase of tissue concentrations could be observed only between the low- and the medium- or highest-dose group.

\section{Adverse Events}

A total of 20 AEs were reported by $9 / 19$ patients (47.4\%). 4/6 (66.7\%), 2/7 (28.6\%) and 3/6 (50.0\%) patients reported AEs in the 100-, 200- and 400-mg group, respectively. The most frequently reported AEs during treatment were gastrointestinal system disorders (diarrhoea, dyspepsia, vomiting). 3 AEs (diarrhoea, ageusia), all occurring in the $400-\mathrm{mg}$ group, were considered by the investigator to be related to study medication (probably or possibly). For 8 AEs, the relationship to study medication was unknown. Most of the AEs $(80 \%)$ were of mild or moderate intensity. There was no death or any $\mathrm{AE}$ leading to premature discontinuation. One serious AE (bronchospasm) in the 100-mg group was reported which was judged to be unrelated to study medication.

There were 2 AEs associated with abnormal laboratory values (severe hypokalaemia and mild hyperkalaemia), both in the 100-mg group. While the event of hypokalaemia was unrelated to study medication, the relationship of hyperkalaemia to study medication was unknown. Otherwise, no clinically meaningful changes in haematology, serum chemistry, and coagulation parameters were found that would give rise to a safety concern related to treatment with WX-671. There were also no clinically meaningful changes in vital signs, including body temperature, physical examination and ECG parameters. 
Fig. 2. Tissue concentrations of WK-UK1 after oral application of the pro-drug WX-671.

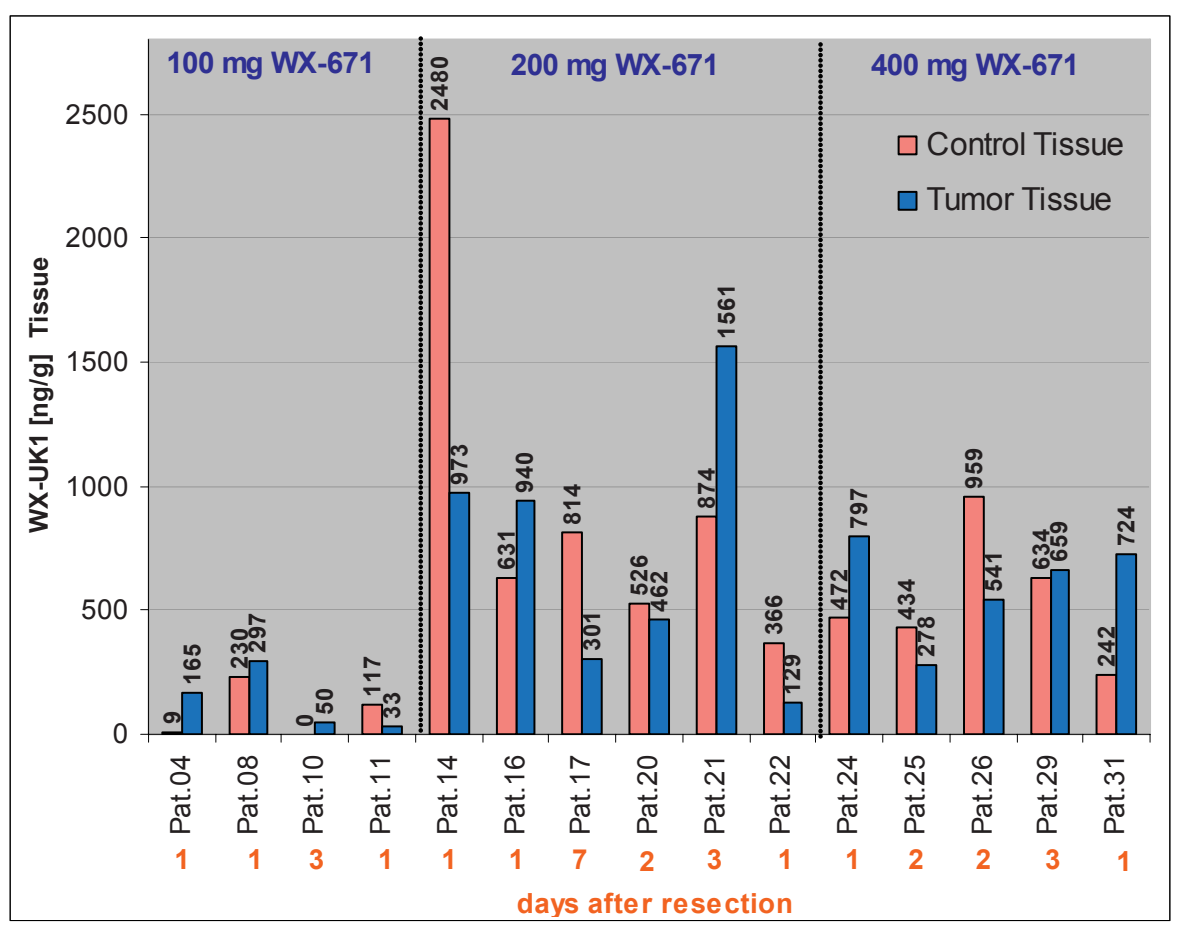

\section{Discussion}

HNSCC is the fifth most common cancer entity worldwide with an extremely bad prognosis, according for an incidence of approximately 80,000 new cancer patients every year in the industrialised countries [20]. Despite improved surgical techniques, implementation of new radiation practices and the application of adjuvant chemotherapy, the 5 -year overall survival rate has remained low and almost unchanged during the last 30 years [21]. So there is an urgent need for adjuvant therapy, especially against the background of early metastatic spread. Here the inhibitors of the uPA system might be of therapeutic value in this carcinoma $[18,19]$.

A total of 19 patients were included in this open-label, single-arm study. The plasma pharmacokinetic data obtained in this study was consistent with the results obtained in a previous healthy-volunteer study. Comparison of the trough levels on days 8 and 15 showed that neither WX-671 nor WX-UK1 accumulate under repeated dosing. Daily doses of $400 \mathrm{mg}$ WX-671 did not result in higher WX-UK1 tissue concentration compared to $200 \mathrm{mg}$ WX-671, suggesting that 200 mg might be the optimum dose. Little to no WX-671 was measurable in tissue at the time of resection, consistent with efficient metabolism and a short half-life of WX-671 in plasma, whereas WX-UK1 concentrations in tissue were at least 15 -fold higher than in plasma. Thus, the tissue concentrations were sufficient for uPA target inhibition.

For safety assessments, data of all patients were used. Due to the small group size, the data needs to be interpreted with due caution and clear dose trends cannot be established. Overall, the patients tol- erated treatment with WX-671 very well, and differences in AE incidences or AE profiles between dose groups were not apparent. Approximately half of the patients $(47.4 \%)$ experienced AEs, of which the great majority was of mild or moderate intensity and judged to be unrelated to study medication. Gastrointestinal system disorders were reported in previous studies and were also the most frequently reported AEs during treatment in this study. Three drug-related AEs were reported (all in the 400-mg group), which included diarrhoea $(2 \times)$ and ageusia, and had all completely recovered under continued treatment. For 8 AEs, including hyperkalaemia, nasopharyngitis, diarrhoea $(3 \times)$ and emesis $(3 \times)$, the relationship to study medication was unknown und thus a causal association with WX-671 treatment cannot be excluded for these AEs. There was only one serious AE (broncho-spasm) which, however, in the opinion of the investigator was unrelated to study medication. Headache, frequently observed in previous studies, was not reported.

No clinically meaningful changes in haematology, serum chemistry, and coagulation parameters were found that would give rise to a safety concern related to treatment with WX-671. An increase in liver enzymes as reported previously was not observed. There were also no clinically meaningful changes in vital signs, including body temperature, physical examination and ECG parameters.

Thus, WX-671 achieves putative therapeutic tissue levels of WX-UK1, with no serious AEs except for minor gastrointestinal system disorders, like diarrhoea. Further trials to investigate the efficacy of WX-671 against metastatic spread of HNSCC are warranted.

\section{References}

$>1$ Reuning U, Magdolen V, Wilhelm O, Fischer K, Lutz V, Graeff H, Schmitt M: Multifunctional potential of the plasminogen activation system in tumour invasion and metastasis (review). Int J Oncol 1998;13:893-906.
Carmeliet P, Collen D: Gene targeting and gene transfer studies of the biological role of the plasminogen/plasmin system. Thromb Haemost 1995; 74:429-436.
Bugge TH, Flick MJ, Danton MJ, Daugherty CC, Romer J, Dano K, Carmeliet P, Collen D. Degen JL: Urokinase-type plasminogen activator is effective in fibrin clearance in the absence of its receptor or tissue-type plasminogen activator. Proc Natl Acad Sci USA 1996;93:5899-5904. 
4 Romer J, Bugge TH, Pyke C, Lund LR, Flick MJ, Degen JL, Dano K: Impaired wound healing in mice with a disrupted plasminogen gene. Nat Med 1996;2:287-292.

5 Duffy MJ, O'Grady P, Devaney D, O'Siorain L, Fennelly JJ, Lijnen HJ: Urokinase-plasminogen activator, a marker for aggressive breast carcinomas. Cancer 1988;62:531-533.

6 Janicke F, Schmitt M, Ulm K, Gossner W, Graeff H: The urokinase-type plasminogen activator (uPA) antigen is related to early relapse in breast cancer. Lancet 1989;2:1049.

7 Hofmann R, Lehmer A, Buresch M, Hartung R, Ulm K: Clinical relevance of urokinase plasminogen activator, its receptor and its inhibitor in patients with renal cell carcinoma. Cancer 1996;78: 487-492.

8 Nekarda H, Siewert JR, Schmitt M, Ulm K: Tumour-associated proteolytic factors UPA and PAI-1 and survival in totally resected gastric cancer. Lancet 1994:34:117.

$\checkmark 9$ Andreasen P, Egelund R, Petersen HH: The plasminogen activation system in tumour growth, invasion, and metastasis. Cell Mol Life Sci 2000;57: 25-40.

10 Muehlenweg B, Sperl S, Magdolen V, Schmitt M, Harbeck, N: Interference with the urokinase plasminogen activator (uPA) system: A promising therapy concept for solid tumours. Exp Opin Biol Ther 2001;1:683-691.
1 Schmitt M, Wilhelm OG, Reuning U, et al.: Urokinase plaminogen activator system as a novel target for tumour therapy. Fibrinolysis Proteolysis 2000; 14:114-132.

2 Janicke F, Prechtl A, Thomssen C, Harbeck N, Meisner C, Untch M, Sweep CG, Selbmann HK, Graeff H, Schmitt M: Randomized adjuvant chemotherapy trial in high-risk, lymph node-negative breast cancer patients identified by urokinasetype plasminogen activator and plasminogen activator inhibitor type 1. J Natl Cancer Inst 2001;93: 913-920.

13 Nozaki S, Endo Y, Nakahara H, Yoshizawa K, Hashiba Y, Kawashiri S, Tanaka A, Nakagawa K, Matsuoka Y, Kogo M, Yamamoto E: Inhibition of invasion and metastasis in oral cancer by targeting urokinase-type plasminogen activator receptor. Oral Oncol 2005;41:971-977.

4 Ertongur S, Lang S, Mack B, Wosikowski K, Muehlenweg B, Gires O: Inhibition of the invasion capacity of carcinoma cells by WX-UK1, a novel synthetic inhibitor of the urokinase-type plasminogen activator system. Int J Cancer 2004;110: 815-824.

15 Rosenthal EL, Johnson TM, Allen ED, Apel IJ, Punturieri A, Weiss SJ: Role of the plasminogen activator and matrix metalloproteinase systems in epidermal growth factor- and scatter factor-stimulated invasion of carcinoma cells. Cancer Res 1998; 58:5221-5230.
6 Schmidt M, Schler G, Gruensfelder P, Muller J, Hoppe F: Urokinase receptor up-regulation in head and neck squamous cell carcinoma. Head Neck 2000;22:498-504.

7 Nozaki S, Endo Y, Kawashiri S, Nakagawa K, Yamamoto E, Yonemura Y, Sasaki T: Immunohistochemical localization of a urokinase-type plasminogen activator system in squamous cell carcinoma of the oral cavity: association with mode of invasion and lymph node metastasis. Oral Oncol 1998;34: 58-62.

18 Strojan P, Budihna M, Smid L, Vrhovec I, Skrk J Urokinase-type plasminogen activator, plasminogen activator inhibitor type 1 and cathepsin D: analysis of their prognostic significance in squamous cell carcinoma of the head and neck. Anticancer Res 2000;20:3975-3981.

19 Strojan P, Budihna M, Smid L, Vrhovec I, Skrk J: Urokinase-type plasminogen activator (uPA) and plasminogen activator inhibitor type 1 (PAI-1) in tissue and serum of head and neck squamous cell carcinoma patients. Eur J Cancer 1998;34: 1193-1197.

20 Vokes EE, Weichselbaum RR, Lippman SM, Hong WK: Head and neck cancer. N Engl J Med 1993 328:184-194.

21 Lang S, Wollenberg B, Dellian M, Steuer-Vogt MK, Schwenzer K, Sautier W, Chucholowski M, Eckel R, Faas I, Wilmes E, Ehrenfeld M, Arnold W, Kastenbauer E, Hölzel D: Clinical and epidemiological data of patients with malignomas of the head and neck. Laryngorhinootologie 2002;81:499-508. 